\title{
CONF-971090--
}

\section{METALLURGICAL BONDING DEVELOPMENT OF V-4Cr-4TI ALLOY FOR THE DIII-D RADIATIVE DIVERTOR PROGRAM}

\author{
by \\ J.P. SMITH, W.R. JOHNSON, AND P.W. TRESTER
}

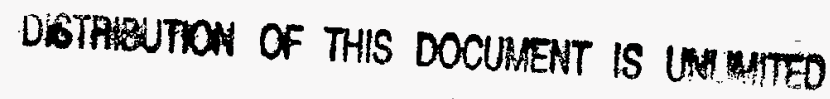

RECEIVED

FFR 101998

OSTI

\section{JANUARY 1998}




\title{
METALLURGICAL BONDING DEVELOPMENT OF V-4Cr-4Ti ALLOY FOR THE DIII-D RADIATIVE DIVERTOR PROGRAM
}

\author{
by \\ J.P. SMITH, W.R. JOHNSON, AND P.W. TRESTER
}

This is a preprint of a paper presented at the Eighth International Conference on Fusion Reactor Materials, (ICFRM-8) October 26-31, 1997, Sendai, Japan, and to be printed in the Proceedings.

\author{
Work supported by \\ U.S. Department of Energy \\ under Contract DE-AC03-89ER51114
}

GENERAL ATOMICS PROJECT 3466

JANUARY 1998 


\title{
Metallurgical bonding development of $\mathrm{V}-4 \mathrm{Cr}-4 \mathrm{Ti}$ alloy for the DIII-D radiative divertor program
}

\author{
J.P. Smith, ${ }^{*}$ W.R. Johnson, and P.W. Trester \\ General Atomics, P.O. Box 85608, San Diego, California 92186-5608, U.S.A.
}

\begin{abstract}
General Atomics (GA), in conjunction with the Department of Energy's (DOE) DIII-D Program, is carrying out a plan to utilize a vanadium alloy in the DIII-D tokamak as part of the DIII-D Radiative Divertor (RD) upgrade. The V-4Cr-4Ti alloy has been selected in the U.S. as the leading candidate vanadium alloy for fusion applications. This alloy will be used for the divertor fabrication.

Manufacturing development with the V-4Cr-4Ti alloy is a focus of the DIII-D RD Program. The RD structure, part of which will be fabricated from $\mathrm{V}-4 \mathrm{Cr}-4 \mathrm{Ti}$ alloy, will require many product forms and types of metal/metal bonded joints. Metallurgical bonding methods development on this vanadium alloy is therefore a key area of study by GA. Several solid-state (non-fusion weld) and fusion weld joining methods are being investigated.

To date, GA has been successful in producing ductile, high-strength, vacuum leaktight joints by all of the methods under investigation. The solid-state joining was accomplished in air, i.e., without the need for a vacuum or inert gas environment to prevent interstitial impurity contamination of the $\mathrm{V}-4 \mathrm{Cr}-4 \mathrm{Ti}$ alloy.
\end{abstract}

Key words: V01, J01

\section{Introduction}

GA has initiated development and designs to fabricate, install, and operate a vanadium alloy divertor structure in DIII-D [1,2]. The use of the vanadium alloy $\mathrm{V}-4 \mathrm{Cr}-4 \mathrm{Ti}$ in various product forms now available will provide a meaningful step toward developing and qualifying this advanced material for fusion power applications by (1) demonstrating the in-service behavior of the vanadium alloy in a typical tokamak environment, and (2) developing knowledge and experience on the design, processing, and fabrication of largescale vanadium alloy components. The overall plan described is being carried out in conjunction with GA and the Materials Program of the Department of Energy's Office of

\footnotetext{
*Present Address: Ismeca, Carlsbad, California, U.S.A.
} 
Fusion Energy (DOE/OFE). The execution of the plan is a joint effort by GA, the DIII-D Program, and DOE Material Program participants [3].

On the basis of excellent properties that have been determined for both laboratoryscale and production-scale heats, $\mathrm{V}-4 \mathrm{Cr}-4 \mathrm{Ti}$ alloy has been identified as a promising alloy for application in fusion reactor structural components [4-6]. This alloy was selected by GA for procurement in product forms applicable for the manufacture of the RD upgrade. A $1200 \mathrm{~kg}$ $\mathrm{V}-4 \mathrm{Cr}-4 \mathrm{Ti}$ alloy ingot has been processed by Wah Chang of Albany, Oregon (WCA), and has been converted into plate, sheet, rod, and tubing [7].

\section{Vanadium alloy radiative divertor component}

A portion of the upper half of the RD structure, the upper private flux baffle, will use $\mathrm{V}-4 \mathrm{Cr}-4 \mathrm{Ti}$ alloy. Other portions will be fabricated from another alloy, Inconel 625 . The $\mathrm{V}-4 \mathrm{Cr}-4 \mathrm{Ti}$ alloy structure will consist of toroidally-continuous, water-cooled structural panels with graphite tiles mechanically attached to the panel surfaces by welded studs (Fig. 1). The panels will be water cooled during machine operation and will experience a maximum temperature of $\sim 60^{\circ} \mathrm{C}$. During DIII-D vessel post-vent clean-up, hot air will replace the water in the coolant channels of the structure, and the structure (along with the DIII-D vessel) will be baked to $\sim 350^{\circ} \mathrm{C}$. The panels will be attached to the vacuum vessel by Inconel 718 supports which will provide the required strength for reacting disruption loads and the flexibility for withstanding differential thermal growth during baking. Due to the lower electrical resistivity of the $\mathrm{V}-4 \mathrm{Cr}-4 \mathrm{Ti}$ alloy, the eddy current flow during disruption will be approximately four times larger than the previous Inconel 625 designs [1].

The panels will be made in segments and fabricated of sandwich construction from two $4.76 \mathrm{~mm}$ sheets, each containing a $1.5 \mathrm{~mm}$ deep coolant channel milled into the panel (Fig. 1). Resistance seam welding is being considered for structurally joining the sheets to form the panel. Electron beam welding will be used to ensure the leak tightness of the panel edges, and is also being considered for making tube connections for water flow to the panels. Inertia and portable friction welding are candidate processes being considered for joining studs to the panels. These studs attach the plasma-facing graphite tile components. Inertia welding and explosive bonding are candidate processes being investigated for making tubeto-tube joint transitions of $\mathrm{V}-4 \mathrm{Cr}-4 \mathrm{Ti}$ alloy to Inconel 625 . These transitions will enable gastungsten arc (GTA) welding at the end of the Inconel 625 tube.

\section{Manufacturing technology development}

The RD structure will require many metal/metal joints, and joining development is therefore a key area of study. The vanadium alloy product forms utilized for these studies have included $\mathrm{V}-4 \mathrm{Cr}-4 \mathrm{Ti}$ and $\mathrm{V}-5 \mathrm{Cr}-5 \mathrm{Ti}$ alloys (Table I) from prior and ongoing programs [5-7]. 


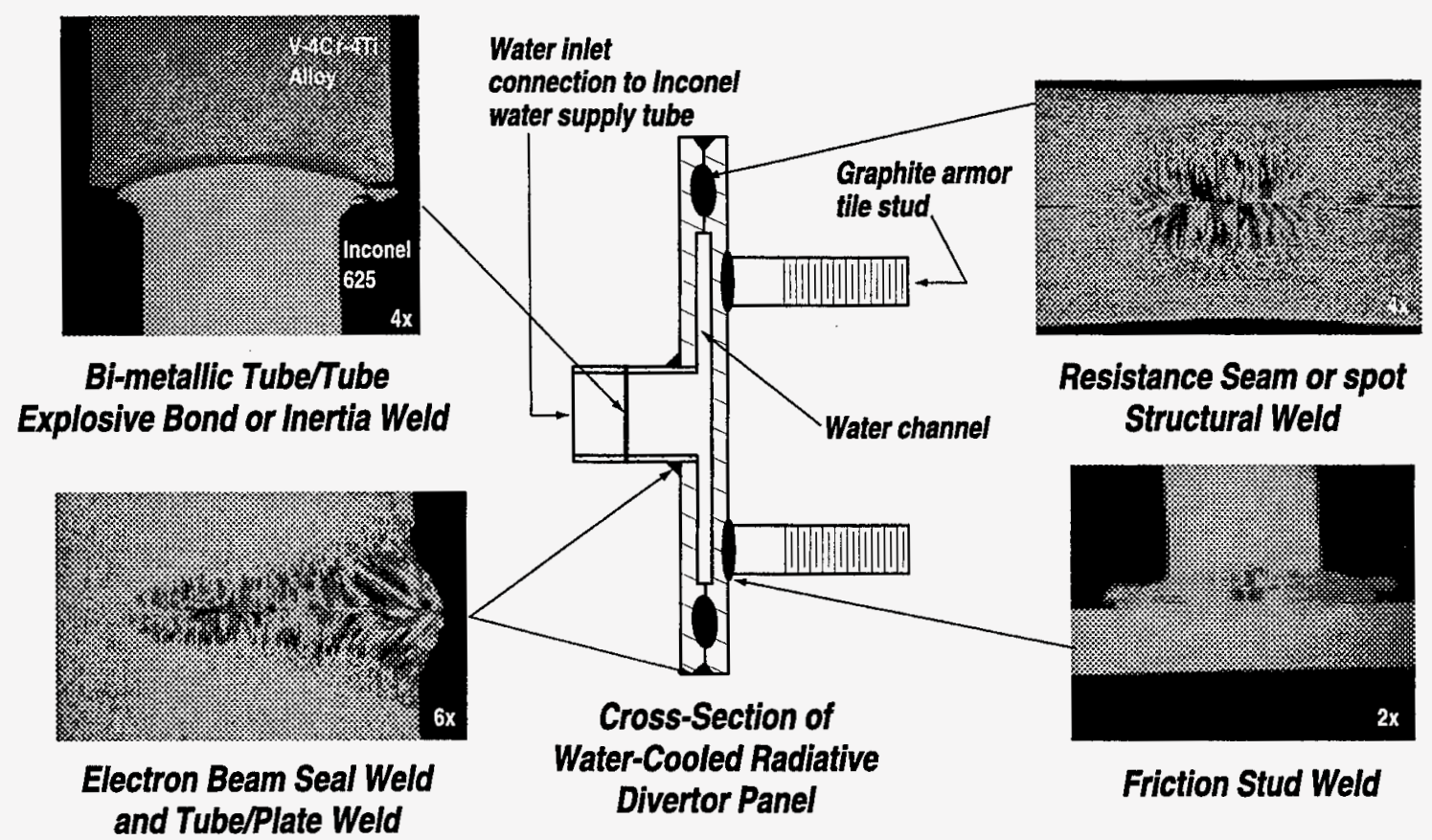

Fig. 1. Cross-section of water-cooled panel for $\mathrm{V}-4 \mathrm{Cr}-4 \mathrm{Ti}$ alloy private flux baffle of DIII-D Radiative Divertor showing locations and types of candidate joining methods to be used in its construction.

\subsection{Resistance welding studies}

Resistance welding is planned for structurally joining two sheets of vanadium alloy together to make the water-cooled panels for the RD structure. There are two primary types of resistance welding: spot and seam welding. A spot weld is made by pressing two or more overlapping sheets of metal between copper electrodes and passing an electrical current through the localized contact area. The contact resistance between the materials produces heat which can increase the temperature at the contacting surfaces and produce local melting. A resistance seam weld is made by development of overlapping spot welds and traversing along the metal. Air is occluded from the joint contact area by virtue of the clamping force during the passage of current, thus preventing pickup of impurities which could embrittle the joint.

Initial resistance weld trials were performed using single spot welds on annealed $3.81 \mathrm{~mm}$-thick $\mathrm{V}-4 \mathrm{Cr}-4 \mathrm{Ti}$ alloy sheet coupons to determine welding parameters. A weld cycle using $12.7 \mathrm{~mm}$ diameter copper electrodes (Class 2) and incorporating a series of two preheat cycles plus two weld cycles, followed by a single forge cycle, was utilized. Weld parameters (preheat and weld power settings, current dwell times, and electrode pressures) were selected based on previous experience with Inconel 625. Some diffusion bonding ( $80 \%-100 \%$ of the interface regions directly under the weld electrodes) was obtained. This indicated that the material had reached $80 \%$ to $90 \%$ of its melting temperature. However, no weld nuggets (melt zones) were observed. These diffusion-bonded samples demonstrated 


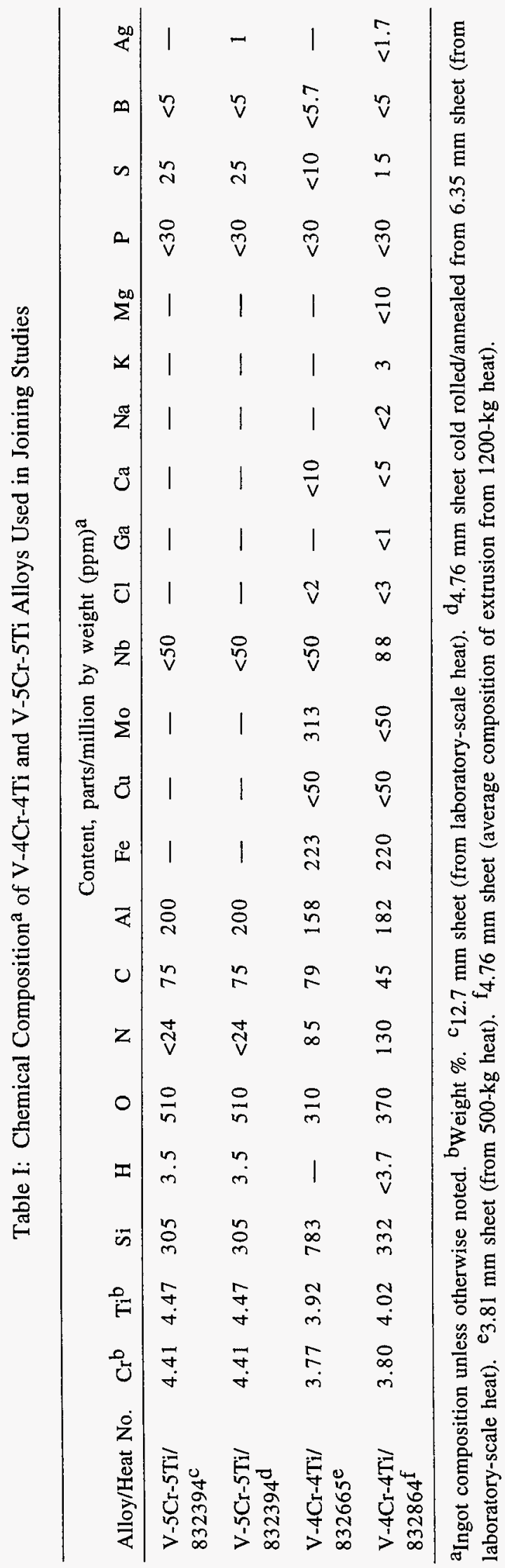


strengths up to $135 \mathrm{MPa}$ in shear tests, but were considerably weaker than that expected based on the tensile properties of the alloy ( $520 \mathrm{MPa}$ ultimate strength).

Additional trials were performed with similar $\mathrm{V}-4 \mathrm{Cr}-4 \mathrm{Ti}$ alloy sheet material using preheat and weld power settings adjusted upward by approximately $20 \%$. These settings were estimated to produce melting between the contacting surfaces. The trials were successful, yielding weld nuggets $\sim 7 \mathrm{~mm}$ in diameter, with a thickness equal to $\sim 80 \%$ of the total coupon thickness, and microhardness values in the weld and heat-affected zones (HAZs) $\sim 10 \%$ greater than that of the wrought sheet (Fig. 1).

Spot weld trials were then performed using V-5Cr-5Ti alloy sheet material available in thickness similar to that to be used for the RD water-cooled panels $(4.76 \mathrm{~mm})$. Power settings for this thickness were increased over that used for the thinner material. These weld trials were also successful, producing diffusion bonds at the lowest power levels and weld nuggets at higher power levels, with diameters varying from $\sim 3.8$ to $\sim 12 \mathrm{~mm}$ in diameter. The nugget width correlated with the average power per unit time in the welding cycle. The weld nuggets generally contained a single, small, centrally-located solidification pore. Nevertheless, the welds $\sim 10 \mathrm{~mm}$ in diameter demonstrated considerable strength in spot weld lap shear tests ( $\sim 685 \mathrm{MPa}$ based on weld nugget diameter only, and $\sim 380 \mathrm{MPa}$ based on total bonded diameter of diffusion bond + weld nugget. The lower strength values reported $(380 \mathrm{MPa})$ were still greater than values specified by American Welding Society (AWS) standards for material of this strength level. Additional spot weld trials were performed on this material using increased electrode (forge) pressures at the end of the weld cycle; the forging reduced the size of the weld porosity.

Joining by resistance seam welding was then performed on similar $4.76 \mathrm{~mm}$-thick V$4 \mathrm{Cr}-4 \mathrm{Ti}$ alloy sheet using copper alloy wheel electrodes. A variety of power settings, and electrode (wheel) pressures, wheel diameters, and wheel radii were investigated. Attempts at producing fully-melted nuggets by utilizing very high power inputs, resulted in some localized edge melting of the copper electrodes, copper penetration into the grain boundaries of the alloy, and surface cracking. Therefore, lower power levels were investigated and seam diffusion bonds ( $\sim 5$ to $10 \mathrm{~mm}$ in width) were obtained. These joints were lap-shear tested and exhibited room-temperature strengths comparable to that achieved for similar spotwelded (and spot-bonded) material. A vacuum leak test of a sectioned $\sim 75 \mathrm{~mm}$ long seambonded sample indicated no leaking at a helium leak rate sensitivity of $<1 \times 10^{-12} \mathrm{~Pa}-\mathrm{m}^{3} / \mathrm{s}$, well below that required for high vacuum DIII-D vessel components.

\subsection{Friction welding studies}

Two types of friction welding trials are in progress. Both inertia and portable friction welding processes have been selected for joining vanadium alloy to itself. Inertia welding has been selected for creating a bi-metallic joint between $\mathrm{V}-4 \mathrm{Cr}-4 \mathrm{Ti}$ alloy and Inconel 625 . Friction welding is a solid-state welding process that produces a fine-grained forged weld by 
using the heat generated between a rotating part contacting a fixed substrate material under an axial pressure load. Unlike conventional welding processes, heat for welding is generated by direct conversion of mechanical energy to thermal energy at the interface of the workpieces, without application of electrical energy or heat from other sources. The pressure hot works the metal interface, expelling any impurities or voids to the outside circumference of the rotating part (in the flash) and refining the grain structure. In portable friction welding, the weld is made by holding a non-rotating workpiece in contact with a rotating workpiece under constant or gradually increasing pressure until the interface reaches the weld/forging temperature. The rotation is then stopped at a predetermined amount of axial travel of the rotating part (burnoff), and axial pressure is maintained for a short period of time to consolidate the weld. In inertia welding, one workpiece is fixed in a stationary holding device. The other, clamped in a spindle chuck, usually with attached flywheel, is accelerated rapidly. At a predetermined speed, driving power is discontinued and the rotating part is thrust axially against the fixed part. Friction between the parts decelerates the flywheel, converting stored energy to friction - enough to soften, but not melt the contacting faces of the parts. Just before rotation ceases, the two parts bond. The weld is complete when the flywheel stops.

\section{Inertia welding studies}

Inertia welding trials were first performed on $\mathrm{V}-5 \mathrm{Cr}-5 \mathrm{Ti}$ alloy to itself $(19.05 \mathrm{~mm}$ diameter $\times 4.76 \mathrm{~mm}$ thick disc to $9.52 \mathrm{~mm}$ diameter rod), and were successful. Metallography showed complete bonding with no indications of porosity or cracking. Microhardness measurements showed only slight increases in hardness in the weld and HAZs. Tensile pull tests were performed on three weld trial specimens at room temperature, and all three samples failed in the $\mathrm{V}-5 \mathrm{Cr}-5 \mathrm{Ti}$ alloy rod well away from the weld areas and reached stress levels of $\sim 520 \mathrm{MPa}$, values comparable to those of the parent metal strength. Torque tests were also performed on two additional samples to measure the capability of the joint to withstand torsion loads as would be experienced in a stud-to-plate joint. Again, failures occurred in the V-5Cr-5Ti alloy rod far from the welded joints.

Trials using $\mathrm{V}-5 \mathrm{Cr}-5 \mathrm{Ti}$ alloy rod $(9.52 \mathrm{~mm}$ diameter) and a smaller diameter $(6.35 \mathrm{~mm})$, Inconel $625 \mathrm{rod}$, to match the forgeabilities of the two materials, were successful. Metallography showed complete bonding with no porosity or cracking (Fig. 1). Tensile pull tests were performed on three weld trial samples. Two samples failed in the Inconel 625 section well away from the weld area (at $\sim 930 \mathrm{MPa}$ stress) and one sample failed at the approximate weld interface, but at a high stress level of $\sim 760 \mathrm{MPa}$. These strength levels are considerably higher than the ultimate tensile strength of the $\mathrm{V}-5 \mathrm{Cr}-5 \mathrm{Ti}$ alloy $(-520 \mathrm{MPa})$, and are attributed to an increase in the strength of the alloy near the joint due to the heavily hot-worked structure (fine grain size) developed by the inertia welding.

Inertia weld trials were then performed to fabricate a bi-metallic $\mathrm{V}-5 \mathrm{Cr}-5 \mathrm{Ti}$ alloy/ Inconel 625 joint in a simulated tube-to-tube butt joint. This configuration can be machined into a bi-metallic tube transition nipple which can then be joined to a vanadium alloy water- 
cooled panel (e.g., by electron beam welding) and subsequently to an Inconel 625 cooling water tube (e.g., by a GTA weld). After initial unsuccessful attempts, followed by a joint configuration change, bi-metallic inertia weld joints were produced which were vacuum leak tight to DIII-D standards $\left(<1 \times 10^{-10} \mathrm{~Pa}-\mathrm{m}^{3} / \mathrm{s}\right)$ and exhibited strengths $\geq 720 \mathrm{MPa}$ in roomtemperature tensile pull tests, with failures occurring by a ductile, tearing mode in the $\mathrm{V}$-alloy away from the joint.

\section{Friction welding studies}

Preliminary portable friction welding trials of $\mathrm{V}-4 \mathrm{Cr}-4 \mathrm{Ti}$ alloy rod to sheet $(9.52 \mathrm{~mm}$ diameter rod to $3.81 \mathrm{~mm}$ thick sheet) were performed to develop a method of joining threaded studs to water-cooled panels. Metallographic evaluation of selected samples from these trials indicated porosity-free bonding over $\sim 100 \%$ of the contacting areas. The HAZ thickness generally decreased with increased ram pressure, for a given ram speed. A roomtemperature tensile pull test performed on a sample processed using an intermediate ram speed failed near the joint at a stress value of $\sim 345 \mathrm{MPa}$, approximately equivalent to the tensile yield strength of the $\mathrm{V}-4 \mathrm{Cr}-4 \mathrm{Ti}$ alloy. An additional series of trials, utilizing threaded studs similar to that to be used for fabricating the RD structure, is currently in progress to explore variations in rotational speed, ram pressure, and stud tip design.

\subsection{Electron beam welding studies}

Preliminary electron beam (EB) welding trials have also been successfully conducted at GA. Initial weld parameters were obtained from ORNL personnel based on previous EB weld research efforts, and weld penetration tests were performed using $6.35 \mathrm{~mm}$ thick $\mathrm{V}-5 \mathrm{Cr}-5 \mathrm{Ti}$ alloy sheet. Weld parameters developed from these trials were used to create a lap weld between two $3.85 \mathrm{~mm}$ thick vanadium alloy sheet materials ( $\mathrm{V}-5 \mathrm{Cr}-5 \mathrm{Ti}$ alloy to $\mathrm{V}-4 \mathrm{Cr}-$ 4Ti alloy). Metallography of the weld indicated good weld penetration with no indications of cracking (Fig. 1). Microhardness measurements showed less than $\sim 10 \%$ increase in hardness across the weld and HAZs, and room temperature tensile tests performed on flat reduced-section specimens produced failures in the parent metal well away from the weld joints and HAZs at values greater than the parent metal strength.

\subsection{Explosive bonding studies}

Explosive bonding has been investigated as an alternate method for producing a dissimilar metal joint between $\mathrm{V}-4 \mathrm{Cr}-4 \mathrm{Ti}$ alloy and Inconel 625 for application as a tube nipple/connector. A lap joint for this tube-to-tube configuration may be more preferable for this application, compared to the butt joint configuration developed by inertia welding, because of the enhanced mechanical stability and a longer interface (leak path).

An explosive bonding trial was performed on an assembly of a $25.5 \mathrm{~mm}$ O.D. $\times 3.3 \mathrm{~mm}$ wall thickness $\mathrm{V}-4 \mathrm{Cr}-4 \mathrm{Ti}$ alloy tube slipped over an Inconel 625 round bar. The result was partially successful; a vacuum leak tight circumferential joint was achieved over about $1 / 2$ of the $\sim 150 \mathrm{~mm}$ assembly length near the end opposite the explosive charge 
detonation point. Dye penetrant inspection and metallography of specimens sectioned along this length of good metallurgical bonding showed no interface porosity. Strength tests of the joint and additional bonding trials are planned. Bonding over the entire length of a trial sample is expected to be achievable by the addition of more explosive material around the outer surface of the tube.

\section{Conclusions}

A program has been developed for utilizing the vanadium alloy $\mathrm{V}-4 \mathrm{Cr}-4 \mathrm{Ti}$ in the Radiative Divertor upgrade for the DIII-D tokamak. Fabrication studies are in progress to develop joining methods applicable to the manufacture of the RD component. Preliminary successes have been achieved in developing metallurgical bonded joints of $\mathrm{V}-4 \mathrm{Cr}-4 \mathrm{Ti}$ alloy by resistance, inertia, portable friction, and electron beam welding methods, and in producing bonding between $\mathrm{V}-4 \mathrm{Cr}-4 \mathrm{Ti}$ alloy and alloy Inconel 625 by inertia welding and explosive bonding methods.

\section{Acknowledgment}

This is a report of work supported by the U.S. Department of Energy under Contract DE-AC03-89ER51114 and by General Atomics under internal R\&D funding.

\section{References}

[1] J.P. Smith, W.R. Johnson, R.D. Stambaugh, P.W. Trester, D. Smith, and E. Bloom, Proc. 16th IEEE/NPSS Symp. Fusion Eng. (1995) 858.

[2] J.P. Smith, W.R. Johnson, R.D. Stambaugh, P.W. Trester, D. Smith, and E. Bloom, J. Nucl. Mater. 233-237 (1996), 421.

[3] W.R. Johnson, J.P. Smith, and K. Richardson, Adv. Mater. Proc. 151 No. 6 (1997) 25.

[4] H. Tsai, D.L. Smith, W.R. Johnson and J.P. Smith, Fusion Reactor Mater. Semiann. Prog. Rep. DOE/ER-0313/21 (1997) 10.

[5] D.L. Smith, H.M. Chung, B.A. Loomis, H. Matsui, S. Votinov, and W. Van Witzenburg, Fusion Eng. Des. 29 (1995), 399.

[6] H.M. Chung, H.-C. Tsai, D.L. Smith, R. Peterson, C. Curtis, C. Wojcik, and R. Kinney, Fusion Reactor Mater. Semiann. Prog. Rep. DOE/ER-0313/17 (1995), 178.

[7] W.R. Johnson and J.P. Smith, Proc. 8th Int. Conf. Fusion Mater. (1997) to be published. 
M98002632

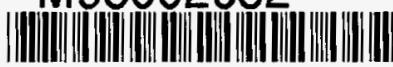

Report Number (14) $6 A-A 22741$

CONF-971090--

subl. Date (11) $\quad 199801$

iponsor Code (18) DOE/ER, XF

IC Category (19) UC-4OO, DOE/ER

DOE 